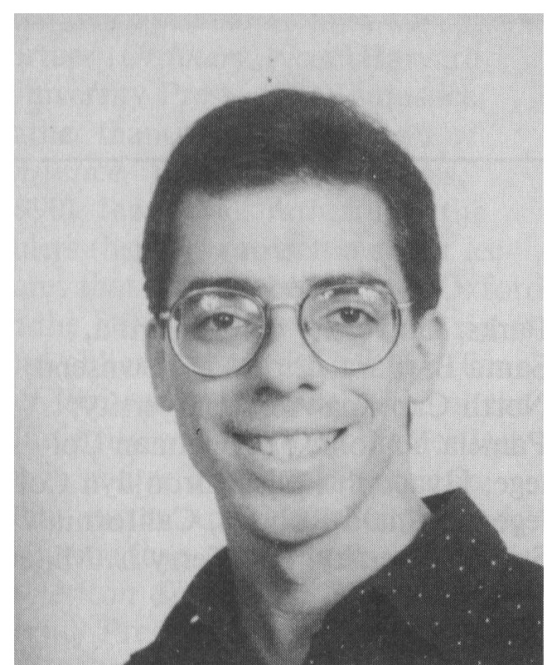

Jose R. Perales-Hernandez

\section{Academic Promise: Placement of New Political Scientists 1992}

\section{Michael Brintnall \\ American Political Science Association}

The APSA has reported on the placement success of graduating classes routinely for some time, and this report follows in the series. The report continues the new practice of reporting every other year, tracking the success of the 1991-92 placement class.

Highlights of the survey are the following:

- $74 \%$ of the placement class found positions, a higher than usual success rate;

- A.B.D.s in particular had greater success than usual, finding positions $66 \%$ of the time, compared to $63 \%$ two years ago and $53 \%$ two years before that;

- one-third of all placements were in temporary positions, higher than two years ago, but not much different from the mean of the last decade;

- placement success rates were highest in American government and public policy; weakest in international relations;

- women were placed at a slightly higher rate than men $(75 \%$ vs. $73 \%$ ), but were less likely to find positions in Ph.D. granting insti-

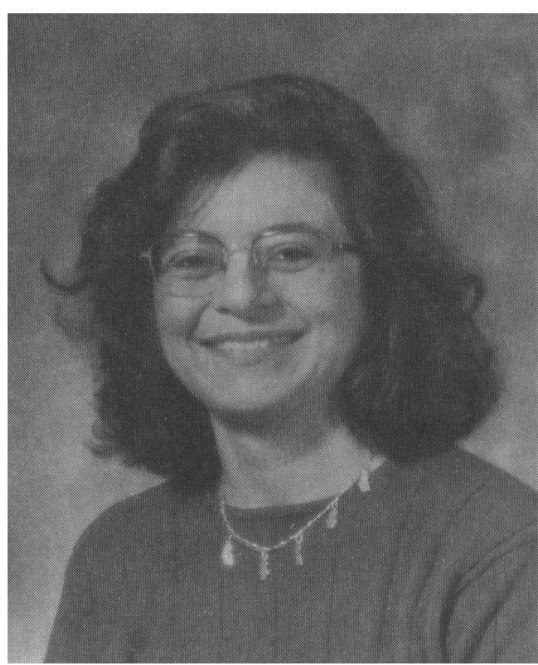

tutions than men; $39 \%$ of the women were placed in Ph.D. schools compared to $48 \%$ of the men in the class.

\section{The Placement Class}

Placement classes represent all students completing or nearing completion of their doctoral programs and entering the job market, typically
Cynthia M. Iglesias seeking academic or related positions

In FY 1991-92, 763 students were reported by 110 departments to be in the placement class. This is based on an $87 \%$ response rate by graduate schools. If non-responding schools are similar to those which responded, the placement class would total 877 students, close in size to the estimated size of the placement class two years ago of 885 students-continuing a trend of large placement

Fifty-nine percent of the class has the Ph.D. in hand; the rest are A.B.D. This is the same as two years ago, and represents a significant increase in the share of A.B.D.s in the placement class compared to the 1980s. The simplest explanation is that the market is readily absorbing A.B.D. students-their placement success has increased in most years since the $1980 \mathrm{~s}$ from under $60 \%$ to $66 \%$ in 1992 .

The University of CaliforniaBerkeley again reports the largest placement class-28 students; however, this number was equalled by the University of Chicago. MIT also reported an especially large class this year, with 22 students. to begin the following academic year. classes.

TABLE 1.

Trends in Placement*

\begin{tabular}{lrrrrrrrr}
\hline & 1982 & 1984 & 1985 & 1986 & 1987 & 1988 & 1990 & 1992 \\
\hline Number of firm candidates & 611 & 672 & 715 & 690 & 604 & 740 & 823 & 763 \\
\% repeats & 36 & 38 & 37 & 32 & 36 & 32 & 32 & 33 \\
\% Ph.D. & 64 & 64 & 69 & 69 & 76 & 64 & 59 & 59 \\
$\%$ women & 21 & 25 & 27 & 26 & 27 & 25 & 26 & 30 \\
\hline
\end{tabular}

*Figures are from 91 departments for 1982 ( $76 \%$ response rate), 83 departments for 1984 ( $71 \%$ response rate), 82 departments in 1985 (68\% response rate), 83 departments for 1986 ( $70 \%$ response rate), 103 departments for 1987 ( $86 \%$ response rate), 115 departments for $1988(92 \%$ response rate), 118 departments for 1990 ( $93 \%$ response rate), and 110 departments for 1992 ( $87 \%$ response rate)

TABLE 2.

Placement Success*

\begin{tabular}{lcccccccc}
\hline & 1982 & 1984 & 1985 & 1986 & 1987 & 1988 & 1990 & 1992 \\
\hline Overall & 62 & 72 & 70 & 69 & 72 & 69 & 72 & 74 \\
Ph.D. & 68 & 77 & 81 & 83 & 80 & 83 & 78 & 79 \\
A.B.D. & 55 & 68 & 51 & 57 & 68 & 53 & 63 & 66 \\
Men & 61 & 72 & 70 & 67 & 70 & 70 & 73 & 73 \\
Women & 64 & 71 & 69 & 74 & 75 & 67 & 70 & 75 \\
Percent placed in & & & & & & & & 32 \\
$\quad$ temporary positions & 36 & 33 & 43 & 38 & 27 & 38 & 21 & 32 \\
$\quad$ Men & 37 & 33 & 43 & 38 & 27 & 38 & NA & 34 \\
$\quad$ Women & 36 & 34 & 43 & 35 & 24 & 33 & NA & 28 \\
\hline
\end{tabular}

*Placement success measures number placed within each category as a percentage of the total can didates within each category. 
TABLE 3.

Placement Success by Field of Specialization, 1986-92 (\%)

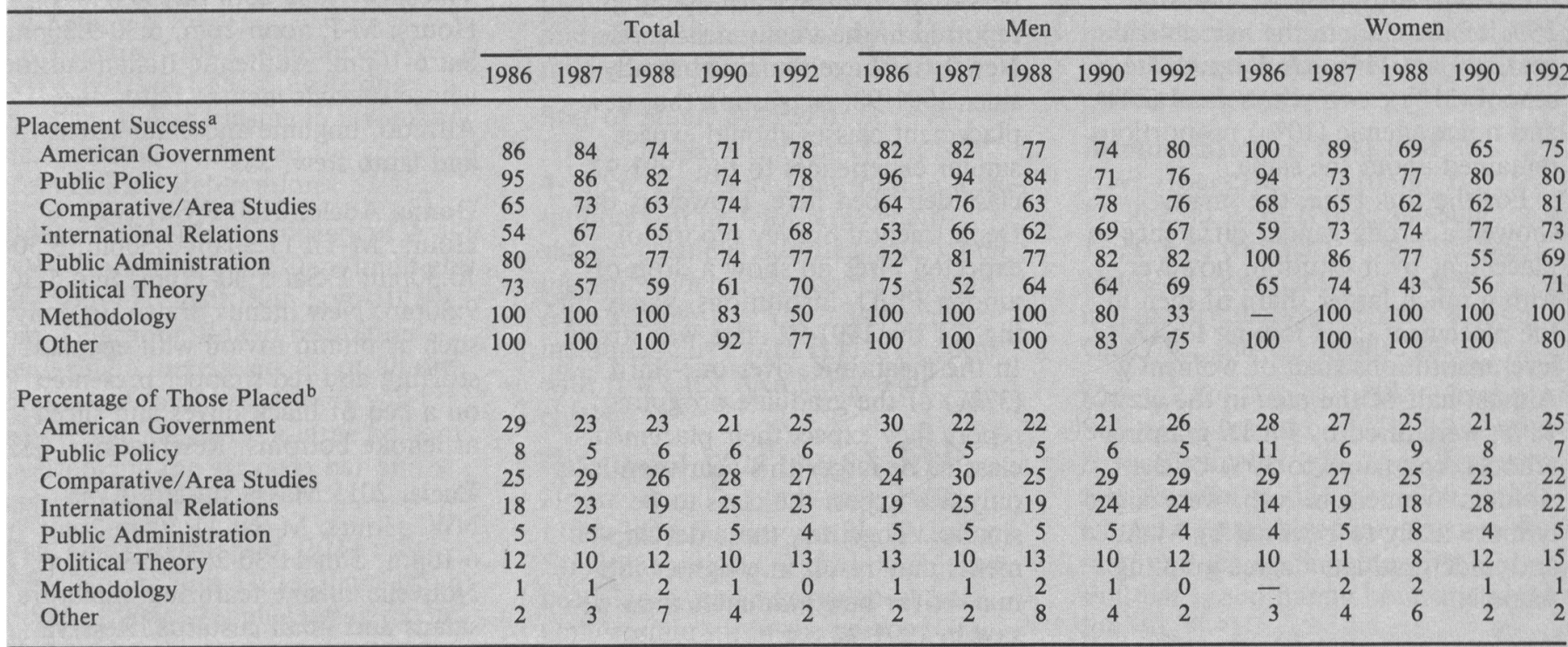

aPlacement success measures number placed in a field as a percentage of total candidates in each of the respective fields.

${ }^{b}$ Percentage of those placed measures the total number placed in a particular field as a percentage of the total number placed in all fields.

TABLE 4.

Placement by Type of Hiring Institution, 1986-92 (\%)

\begin{tabular}{|c|c|c|c|c|c|c|c|c|c|c|c|c|c|c|c|}
\hline & \multicolumn{5}{|c|}{ Total } & \multicolumn{5}{|c|}{ Men } & \multicolumn{5}{|c|}{ Women } \\
\hline & 1986 & 1987 & 1988 & 1990 & 1992 & 1986 & 1987 & 1988 & 1990 & 1992 & 1986 & 1987 & 1988 & 1990 & 1992 \\
\hline Ph.D. department & 41 & 41 & 40 & 41 & 45 & 41 & 40 & 39 & 42 & 48 & 41 & 44 & 44 & 39 & 39 \\
\hline M.A. department & 16 & 15 & 17 & 16 & 11 & 16 & 16 & 16 & 15 & 10 & 18 & 12 & 20 & 21 & 14 \\
\hline $\begin{array}{l}\text { Undergraduate political science or } \\
\text { combined }\end{array}$ & 32 & 30 & 33 & 32 & 31 & 33 & 29 & 36 & 33 & 29 & 31 & 32 & 25 & 31 & 33 \\
\hline Two-year college & 1 & 2 & 2 & 2 & 2 & 1 & 2 & 2 & 2 & 2 & 1 & 2 & 2 & 3 & 3 \\
\hline Nonacademic & 9 & 12 & 8 & 10 & 10 & 9 & 13 & 8 & 12 & 10 & 9 & 10 & 9 & 6 & 11 \\
\hline Total & 99 & 100 & 100 & 101 & 99 & 100 & 100 & 100 & 101 & 99 & 100 & 100 & 101 & 100 & 100 \\
\hline
\end{tabular}

\section{Placement Success}

About three-quarters $(74 \%)$ of the job candidates in AY 1991-92 found positions. This is a higher success rate than usual-in the 1980s placement success rates hovered around $70 \%$, as shown in Table 2. As usual, candidates holding the Ph.D. degree fared better than their counterparts who were A.B.D.-79\% of Ph.D. holders found positions. But the more interesting finding, as noted, is that A.B.D. students found placement at a significantly higher rate than has been the case in the previous 10 years. About a third of all placements were in temporary positions, higher than two years ago, but not inconsistent with experience in the last decade.

Women are a larger share of this placement class than ever before-
$30 \%$ of the placement class. Three quarters of the women in the class found positions this year, slightly exceeding the rate for men, though this has gone both ways in recent years. As has typically been the case in the past, women were more likely to find permanent positions- $28 \%$ of the women in the class accepted temporary positions, compared to $34 \%$ of the men.

\section{Field of Specialization}

Comparative politics and area studies remained the field in which most placements were made. Comparative and international relations together account for half of all academic placements. One-quarter of appointments are in American politics along with $6 \%$ in public policy, $4 \%$ in public administration, $13 \%$ in political theory, $2 \%$ in other fields, and truly just a handful of individuals in political methodology. There are no unambiguous trends suggesting shifting fortunes in recent years among these fields.

Among the more popular fields, placement success lagged only in international relations where $68 \%$ of the class found positions compared to $77 \%$ for comparative politics and $78 \%$ for Americanists. Political theorists fared better than usual. Theorists historically have about a $60 \%$ placement success rate; $70 \%$ found new positions in AY 1991-92.

\section{Institution}

Ph.D.-granting institutions took an even larger share of the placement class than usual-hiring $45 \%$ of the 
class. Master's departments in turn hired a relatively small proportion of the group-dropping from about $16 \%$ of the class in the last several years to just $11 \%$. Undergraduate school $(31 \%)$, two-year school $(2 \%)$, and nonacademic $(10 \%)$ proportions remained about the same.

For the first time, the survey showed a strong gender difference in placement by institution, however, with a much larger share of men in the placement class joining Ph.D. level institutions than of women. Almost half of the men in the class, $48 \%$, were hired by Ph.D. granting schools, compared to $39 \%$ of the women. Women, in turn, were slightly more likely to be hired by M.A. and undergraduate degree granting schools.

\section{Minority Placement}

There were 38 African-American students in the placement class and 26 Latinos, a continued increase in numbers over previous classes. The 1990 placement class included 36 African-American and 21 Latino candidates. Placement of AfricanAmerican candidates mirrored the class as a whole $-74 \%$ found positions.

Placement of Latino students improved dramatically over that of two years ago. This year, almost all of the Latino candidates in the class, $88 \%$, found positions. Two years ago, just half of the Latino candidates had been placed.

Of 29 Asian-American candidates in the placement class, just $62 \%$ were placed this year. However, placement of those Asian-American candidates with the Ph.D. in hand was at the $80 \%$ rate.

\section{Jobs in Political Science}

Overall, the AY 1991-92 placement class in political science has had a relatively successful year, allaying concerns about a possibly lackluster job market. This is especially encouraging since this placement class entered the market in a year in which actual job listings, as identified in the APSA Personnel Service Newsletter, had shown a significant drop from previous years-down by $18 \%$ from 1989-91 levels when listings had been unusually strong.
There are conflicting signals for the 1992-93 placement class. Numbers of political science openings reported in the Personnel Service Newsletter have remained steady since 1991-92, suggesting that new placement classes should expect similar experiences to the 1991-92 class described here. However, the Departmental Survey reports of expected hires do show a drop-off among Ph.D. institutions, where hiring for the 1991-92 class was strong. In the meantime, over one-third $(37 \%)$ of the graduate programs report they expect their placement class to be larger this year than last; only $8 \%$ expect the class to be smaller. Together, these developments may result in a tighter job market for new graduates than we saw in 1991-92.

\section{Washington Restaurants: Annual Meeting Dining Guide}

\section{Diana Falls}

One of the most enjoyable aspects of visiting Washington, D.C. is sampling the many fantastic and diverse restaurants. Diners can enjoy a superb selection of international cuisine to please anyone's palatefrom French, Italian, and Indian to Mexican, Ethiopian, American, and Thai. The following restaurants are highly recommended and are all within walking distance from the Washington Hilton \& Towers, Sheraton and Omni-Shoreham. This list is by no means inclusive and diners will no doubt have luck finding a cozy restaurant on their own if they do a bit of window-shopping. We have begun the list with restaurants in the Dupont Circle area, but for the more adventurous diner, Adams Morgan is just around the corner where virtually any cuisine can be tasted.

The cost of dinner for two, including cocktail, appetizer, entree plus tax and $15 \%$ tip is the basis for the following scale: $\$ 40$ or less, $\$$; $\$ 41-75, \$ \$ ; \$ 76-140, \$ \$ \$$; and more than $\$ 140, \$ \$ \$ \$$. Bon Appetit!

\section{DUPONT CIRCLE}

Vincenzo, 1606 20th St., NW. Hours: M-F noon-2pm, 6:30-9:30pm; Sat $6-10 \mathrm{pm}$. Authentic Italian cuisine whose specials include fettuccine Alfredo, linguine and clam sauce, and lamb stew. $\$ \$ \$$

Donna Adele, 2100 P St., NW. Hours: M-Th 11:30am-2:30pm, 5:3010:30pm; F-Sat 5:30-11 pm; Sun 5:309:30pm. New menus drawn up daily, such as plump ravioli with eggplant stuffing and red snapper presented on a bed of black olives and sliced artichoke bottoms. Reservations. \$\$

Lucie, 2015 Massachusetts Ave., NW. Hours: M-Sat 11:30am-2pm; 6-10pm; Sun 11:30-2:30, 6-9:30pm. Nouvelle cuisine featuring miniature salads and small custards. Reservations. $\$ \$ \$ \$$

Obelisk, 2029 P St., NW. Hours: M-Sat 6-10pm. Italian cuisine. Offers a fixed price of $\$ 33$, enjoy four- or five-course menus with choice of cheese or dessert or both. $\$ \$ \$$

Pizzeria Paradiso, 2029 P St., NW. Hours: M-Th 11am-11pm; F-Sat 11 am-midnight; Sun noon-10pm. A must visit for pizza lovers, offering authentic style crusts with unusual toppings. $\$$

Cafe Luna, 1633 P St., NW. Hours: M-Th 8am-11:30pm; F 8am-2am; Sat 10am-2am; Sun 10am-11:30pm. Italian cuisine. Voted "50 Best Values" in Washington Post. Featuring fresh pasta, pizza and salads. Great cappuccino and desserts. \$

City Lights of China, 1731 Connecticut Ave., NW. Hours: M-Th 11:30am-10:30pm; F 11:30-11pm; Sat noon-11 pm; Sun noon-10:30pm. Featuring Hunan style Northern Chinese cuisine in a cozy atmosphere. $\$$

Joe and Moe's Restaurant, 1211 Connecticut Ave., NW. Hours: M-F 7:30am-10:30pm; Sat 6pm-1 am (big band dancing). World famous steak and seafood house/nightclub. American cuisine with menus available in Spanish, French, Japanese, Arabic, and German. $\$ \$ \$$

Kramerbooks \& Afterwords Cafe, 1517 Connecticut Ave., NW. Hours: Sun-Th 7:30am-1am; 24 hours F-Sat. Full-service restaurant featuring fresh 